\title{
Assessment of Free Anterolateral Thigh Flap for Extremity Reconstruction
}

\author{
HELMY ELWAKEEL, M.D.
}

The Department of Plastic Surgery, Faculty of Medicine, Alexandria University, Egypt

\begin{abstract}
Background: Free tissue transfer has undergone substantial improvement over the past three decades, focusing on functional and aesthetic results of reconstruction for both the donor and recipient sites. The free ALT flap is atypical example of this revolution from its early description by Song et al., in 1984 and its later popularization and wide use to reconstruct defects all over the body from the head to toes yielding very good functional and aesthetic results with relatively minimal donor site morbidity making it a workhorse free flap. For limb reconstruction, it provides a good size of many tissue types including skin, subcutaneous fat, muscle, and fascia with possible sensate flap and flow-through flap for limb revascularization. The flap pedicle is of adequate size and length, 2 team approach is possible, and donor site morbidity is minimal especially with direct closure.
\end{abstract}

Patients and Methods: From April 2016 - December 2018, 11 male patients aged 5-41 years (mean 27.5 years) with extremity defects including 6 upper limbs and 5 lower limbs defects were reconstructed using free ALT flap. Defects were caused by RTA ( 8 cases), electrical burn (1 case), and release of contractures (2 cases).

Results: All flaps survived completely except one case suffered slowly progressive congestion ending in partial flap loss, managed by debridement and skin grafting. Except for one flap harvested as musculocutaneous, all flaps were fasciocutaneous. Flaps perforator pattern were musculocutaneous in $81.9 \%$ of cases and septocutaneous in $18.1 \%$ of cases. 9 flaps were based on a single perforator, 2 and 3 perforators each vascularized one flap.

Conclusion: Free ALT flap is a reliable, versatile reconstructive option for small to moderately large limb defects. Donor site morbidity is minimal with direct closure.

Key Words: Free anterolateral thigh flap - Limb reconstruction - Hand dorsum.

\section{INTRODUCTION}

First introduced by Song et al., in 1984 [1], the anterolateral thigh flap (ALT) is currently a workhorse reconstructive option for many small to moderately large defects requiring skin(with a range of subcutaneous fat offered by flap thinning), fascia, or muscleor any cocktail of them all. The vascular basis of all these tissue components is the descending branch of the lateral circumflex femoral artery (DB-LCFA), running in the septum between the rectus femoris and the vastus lateralis muscles, supplying both and sending perforators to the overlying skin either directly through the fascial septum or through vastus lateralis [2,3]. Initially,it was reported that the direct septocutaneous perforators pattern is more common compared to its musculocutaneous variant [1]. Laterdetailed description of the flap and its vascular basisrevealed the musculocutaneous perforator pattern through the vastus lateralis is more frequently encountered $[2,3]$.

A lot of factors underly the frequent use of this flap: The minimal donor site morbidity, relatively easy dissection (especiallyseptocutaneous perforator based flaps and musculocutaneous flap variant), a large pedicle of good length, various tissue type available for harvest (as one unit or chimeric) on the same vascular basis including the possibility of flap division to more than one skin paddle based on multiple perforators and the possibility of 2 teams working simultaneouslyon the donor and recipient for most of the flap indications $[4,5]$. A flow-through flap option is also a great advantage of this flap for combined vascular and soft tissue reconstruction [6]. A pre-operative vascular mapping with a CT angiogram is of great help for complex flap design as multiple skin paddle or chimeric flaps [7]. The latter chimeric flap option is a great advantage of the lateral circumflex femoral vascular axis [8].

The current report represents the author's experience of limb reconstruction using the ALT flap. Aim:

Reporting the indications, complications, and outcome of extremity reconstruction using the free ALT flap. 


\section{PATIENTS AND METHODS}

During the period between April 2016 - December 2018, in Alexandria main University Hospital, a total of 11 male patients with an upper limb (6 cases) and lower limb (5 cases) defects were reconstructed using a free ALT flap. Patients' age ranged from 5-44 years (mean 27.5 years). Defect size ranged from $5 \times 9 \mathrm{~cm}$ to $11 \times 18 \mathrm{~cm}$. Defects were caused by RTA ( 8 cases), electrical burn (1 case), and release of contractures (2 cases). Informed consent was taken in all cases.

\section{Skin marking:}

The contralateral thigh was chosen for flap harvest. A line connecting ASIS and the superolateral patellar border was marked representing the septum between the vastus lateralis and the rectus muscle. The desired flap/skin paddle was initially centered around its middle point. The final skin paddle location and perforator choice were based on the surgical exploration of the donor site.

\section{Surgical technique:}

All cases were operated upon under general anesthesia. Initially under tourniquets control the recipient vessels were explored and preprepared after debridement of traumatic defects or the release of presented scar contracture. The defect dimensions redetermined the desired flap size more accurately.

\section{Septocutaneous perforator pattern:}

Flap dissection started by incising the medial edge of the skin paddle. Subfascial plane dissection followed on top of rectus femoris muscle reaching the septum between it and vastus lateralis muscle. If appropriate size septocutaneous perforator(s) was encountered the dissection proceeded on the medial surface of the facial septum by medial retraction of the rectus femoris muscle exposingand carefully dissecting the perforator and then the deeply seated DB-LCFA at the base of the septum for the desired pedicle length while carefully cauterizing anymuscular side branches. This was followed by incision of the lateral edge of the skin paddle and subfascial dissection on top of the vastus lateralis muscle approaching the lateral surface of septum and the identified perforator(s) and the already dissected DB-LCFA bylateral retraction of the vastus lateralis muscle. Now the flap is ready for division.

\section{Musculocutaneous perforator pattern:}

Failure to find septocutaneous perforators at the initial medial flap dissection described above was followed by dissection through the fascial septum to approach the surface of vastus lateralis muscle seeking any musculocutaneous perforator(s). The latter once identified was carefully dissected through the muscle towards their source from the DB-LCFA that was exposed in the septum between the rectus and vastus muscles as described above (Fig. 2B) and completely dissected proximally for the desired pedicle length. The skin paddle lateral edge was incised after completion of perforator(s) and proximal pedicle dissection with flap pedicle ready for division.

\section{Musculocutaneous flap harvest:}

Just in one case, 3 small musculocutaneous perforators were identified as having a long intramuscular course a situation that promoted conversion into musculocutaneous flap variant instead of tedious risky dissection of 3 small mucocutaneous perforators that would end by severely traumatized/ poorly functioning muscle segment at the best. The plane modification also included reduction of skin paddle width as allowed by perforator location toensuredirect closure of the donor site. The desired flap width was gained by a cautious lateral slide of the skin paddle over the harvested vastus lateralis muscle strip while ensuring perforator integrity. The skin paddle was resecured in this new potion by quilting sutures to avoid accidental perforators shear (Fig. 3).

\section{Follow-up:}

The post-operative protocol included proper hydration, limb elevation, and close flap monitoring every hour during 1 st 24 hours, every 2 hours during $2^{\text {nd }} 24$ hours then every 3 hours for 5 days. Monitoring was clinical and included skin color, temperature, and capillary refilling. Prophylactic anticoagulant (low molecular weight heparin $1 \mathrm{unit} / \mathrm{kg} /$ day given on 2 divide doses) was given for 10 days, and low dose aspirin for 8 weeks. Limb immobilization continued for 2 weeks postoperative followed by gradual range of motion exercise. Continuous limb elevation continued for 6 weeks before gradual dependency was allowed.

Follow-up assessed other possible early complications including, infection, or delayed healing. When needed flap debulking was initiated at least 6 months after 1ry surgery by incising 50\% of flap circumference at maximum and excising deep fat. As indicated, this could be repeated after 3 months or more. 


\section{RESULTS}

Patients characteristics and results are summarized in Table (1). Eleven male patients with upper (6 cases) or lower limb (5 cases) defects were reconstructed by free ALT flap were included in this study. Mean follow-up was 10.9 months.

Table (1): Summery of patients' demographic data and results.

\begin{tabular}{|c|c|c|c|c|c|c|c|c|}
\hline & Age & $\begin{array}{c}\text { Defect } \\
\text { Location/cause/size }\end{array}$ & Flap Type/size & $\begin{array}{l}\text { Perforator } \\
\text { No./pattern }\end{array}$ & Recipient & Follow-up & Outcome & Complication \\
\hline 1 & 44 & $\begin{array}{l}\text { UL. Lt hand \& wrist } \\
\text { with lost finger } \\
\text { extensors } / \text { electrical } \\
\text { burn } / 8 \times 10 \mathrm{~cm}\end{array}$ & $\begin{array}{l}\text { Fasciocutaneous } \\
8 \times 12 \mathrm{~cm}\end{array}$ & 1/Musculocutaneous & $\begin{array}{l}\text { Redial artery } \\
\text { End to end }\end{array}$ & 6 months & $\begin{array}{l}\text { Successful-later } \\
1 \text { stage of flap } \\
\text { thinning }\end{array}$ & $\begin{array}{l}\text { Minor dehiscence } \\
\text { of donor site }\end{array}$ \\
\hline 2 & 18 & $\begin{array}{l}\text { UL. Rt. } 1^{\text {st }} \\
\text { webspace/ } \\
\text { post traumatic } \\
\text { contracture/6x15 }\end{array}$ & $\begin{array}{l}\text { Fasciocutaneous } \\
7 \times 18 \mathrm{~cm}\end{array}$ & 1/Musculocutaneous & $\begin{array}{l}\text { Redial artery } \\
\text { End to side }\end{array}$ & 28 months & $\begin{array}{l}\text { Successful-later } \\
1 \text { stage of flap } \\
\text { thinning }\end{array}$ & \\
\hline 3 & 5 & $\begin{array}{l}\text { UL. Rt Dorsal hand } \\
\text { with extensor tendon } \\
\text { loss/RTA/6x } 12 \mathrm{~cm}\end{array}$ & $\begin{array}{l}\text { Fasciocutaneous } \\
6 \times 14 \mathrm{~cm}\end{array}$ & 1/Musculocutaneous & $\begin{array}{l}\text { Redial artery } \\
\text { End to end }\end{array}$ & 39 months & $\begin{array}{l}\text { Successful-later } \\
\text { staged flap } \\
\text { thinning }\end{array}$ & \\
\hline 4 & 25 & $\begin{array}{l}\text { UL. Lt wrist/release of } \\
\mathrm{PBC} / 6 \times 13 \mathrm{~cm}\end{array}$ & $\begin{array}{l}\text { Fasciocutaneous } \\
7 \times 15 \mathrm{~cm}\end{array}$ & 1/Musculocutaneous & $\begin{array}{l}\text { Redial artery. } \\
\text { End to side }\end{array}$ & 3 months & $\begin{array}{l}\text { Partial flap } \\
\text { loss/managed } \\
\text { by SSG. }\end{array}$ & \\
\hline 5 & 28 & $\begin{array}{l}\text { UL. Rt distal forearm } \\
\text { with exposed } \\
\text { flexor tendons/ } \\
\text { RTA/5x9 }\end{array}$ & $\begin{array}{l}\text { Fasciocutaneous } \\
6 \times 20 \mathrm{~cm}\end{array}$ & 2 septocutaneous & $\begin{array}{l}\text { Radial artery } \\
\text { End to end }\end{array}$ & 6 months & Successful & \\
\hline 6 & 22 & $\begin{array}{l}\text { UL. Rt hand dorsum } \\
\text { with extensor } \\
\text { tendon loss/ } \\
\text { RTA/7x13 }\end{array}$ & $\begin{array}{l}\text { Fasciocutaneous } \\
8 \times 17 \mathrm{~cm}\end{array}$ & 1/Musculocutaneous & $\begin{array}{l}\text { Radial artery } \\
\text { End to end }\end{array}$ & 3 months & Successful & \\
\hline 7 & 21 & $\begin{array}{l}\text { LL. dorsum of foot/ } \\
\text { RTA } / 11 \times 18 \mathrm{~cm}\end{array}$ & $\begin{array}{l}\text { Musculocutaneous } \\
11 \times 21 \mathrm{~cm}^{*}\end{array}$ & 3/Musculocutaneous & $\begin{array}{l}\text { ATA } \\
\text { End to end }\end{array}$ & 14 months & Successful & $\begin{array}{l}\text { Late osteomyelitis } \\
\text { of } 1^{\text {st }} \& 2^{\text {nd }} \\
\text { metatarsal. }\end{array}$ \\
\hline 8 & 42 & $\begin{array}{l}\text { LL. Distal } 1 / 3 \text { tibia/ } \\
\text { RTA/6x } 10 \mathrm{~cm}\end{array}$ & $\begin{array}{l}\text { Fasciocutaneous } \\
8 \times 16 \mathrm{~cm}\end{array}$ & 1/Musculocutaneous & $\begin{array}{l}\text { PTA } \\
\text { End to side }\end{array}$ & 6 months & Successful & \\
\hline 9 & 23 & $\begin{array}{l}\text { LL. Lt foot dorsum/ } \\
\text { RTA/ } 8 \times 10\end{array}$ & $\begin{array}{l}\text { Fasciocutaneous } \\
8 \times 18 \mathrm{~cm}\end{array}$ & $\begin{array}{l}\text { 1/septocutaneous } \\
\text { (the oblique branch) }\end{array}$ & $\begin{array}{l}\text { ATA } \\
\text { End to end }\end{array}$ & 6 months & Successful & \\
\hline 10 & 39 & $\begin{array}{l}\text { Rt. LL. Distal 1/3 } \\
\text { leg/RTA/8x12cm }\end{array}$ & $\begin{array}{l}\text { Fasciocutaneous } \\
8 \times 17 \mathrm{~cm}\end{array}$ & 1/Musculocutaneous & $\begin{array}{l}\text { PTA } \\
\text { End to side }\end{array}$ & 6 months & Successful & \\
\hline 11 & 36 & $\begin{array}{l}\text { LL. dorsum of foot/ } \\
\text { RTA } / 7 \times 10 \mathrm{~cm}\end{array}$ & $\begin{array}{l}\text { Fasciocutaneous } \\
8 \times 17 \mathrm{~cm}\end{array}$ & 1/Musculocutaneous & $\begin{array}{l}\text { ATA } \\
\text { End to end }\end{array}$ & 3 months & Successful & \\
\hline
\end{tabular}

*Skin paddle width was $7 \times 21 \mathrm{~cm}$. ATA: Anterior tibial artery. PTA: Posterior tibial artery.

Flap size ranged from $6 \times 14 \mathrm{~cm}$ to $11 \times 21 \mathrm{~cm}$. Flap perforators were musculocutaneous in 9 cases (81.9\%) and septocutaneous in 2 cases $(18.1 \%)$. Pedicle length ranged from $7-12 \mathrm{~cm}$, and vessel diameters were ranged from $2-2.5 \mathrm{~mm}$ in adult cases (vessel diameter was about $1.5 \mathrm{~mm}$ in the 5 years old child). Flaps were harvested based on a single perforator in 8 cases, 2 perforators in one case, and 3 small perforators in one case. The latter was the only musculocutaneous flap variant in this series (all other flaps were fasciocutaneous) and used to reconstruct the largest defect of $11 \times 18 \mathrm{~cm}$ on the dorsum of the left foot. This case was presented 1 year later by chronic osteomyelitis of $1^{\text {st }}$ and $2^{\text {nd }}$ metatarsals and was successfully managed with sequestrectomy and bone graft.

All flaps were successful except in one case with partial flap loss secondary to slowly progressive congestion, managed by debridement and split-thickness skin grafting of underlying granu- lating flap subcutaneous fat and fascia. The affected case was a post-burn contracted wrist release.

Flaps skin paddle size width range was $6-8 \mathrm{~cm}$. All donor sites were closed directly, with one minor donor site dehiscence managed by 2ry sutures.

UL defects included 3 cases with dorsal hand and wrist defects with extensor tenon gap reconstructed by fascia Lata, one case of volar postburn contracted wrist which suffered congestion and partial loss managed by skin grafting, one case of $1^{\text {st }}$ web space contracture, and one case with distal volar forearm defect with exposed flexor tendons and associated fracture radius. Aggressive primary flap thinning was performed in the 1st webspace case, preserving only a $3 \mathrm{~cm}$ radius of peri perforator deep fat. Secondary thinning procedures were performed in the 3 dorsal hand defect cases to improve hand shape and function 6-month post-operative or later, they regained fair to poor 
finger range of motion at the MCP joint. The $1^{\text {st }}$ web space flap also receiveda minor secondary thinning procedure.

LL cases included 3 dorsal foot defects with exposed fractures metatarsals and 2 cases with distal third leg defect with open tibial fracture fixed by an external fixator. Flap bulk was appropriate for the distal third leg defects, moderately bulky for the foot defects, especially the case that received the only musculocutaneous flap variant in this series.

All steps (recipient preparation, flap harvest, and microvascular anastomosis) were carried sequentially by a single team, only donor site closure was performed simultaneously during flap anastomosis. Total operative time ranged from $4 \mathrm{~h}-5 \mathrm{~h}$ $35 \mathrm{~min}$ (mean $4 \mathrm{~h} 43 \mathrm{~min}$ ).
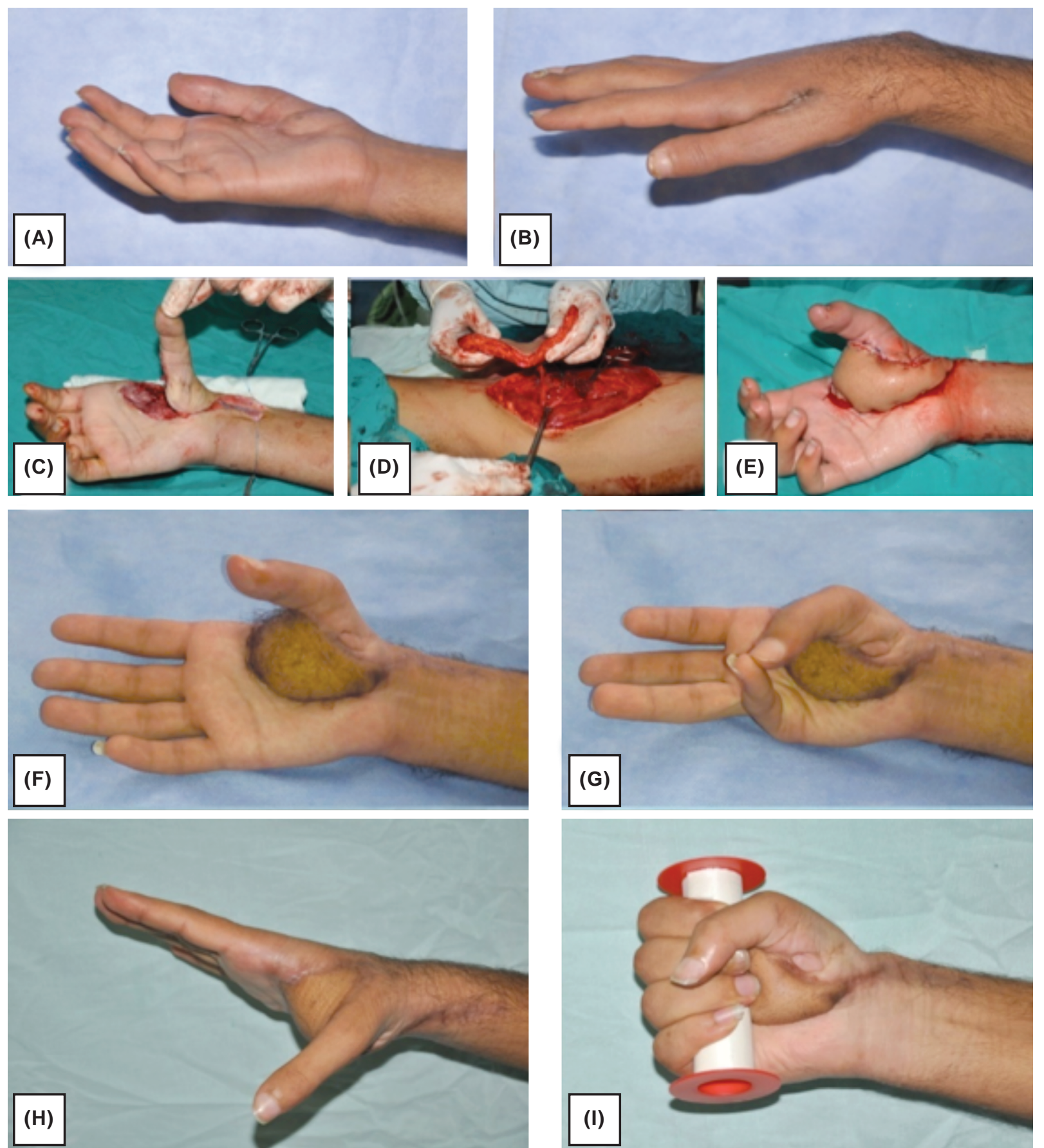

Fig. (1): 18 years old male patient with post-traumatic contracted right $1^{\text {st }}$ webspace. (A\&B) pre-operative view (C) After surgical release preserving any remaining thenar muscles fibers. Recipient radial vessels are seen. (D) Intraoperative view of fasciocutaneous ALT flap based on single musculocutaneous perforator just before pedicle division and before 1ry thinning $(\mathrm{F}, \mathrm{G}, \mathrm{H} \& \mathrm{I}) 2$ years post-operative results and thumb function after one stage of thinning. 

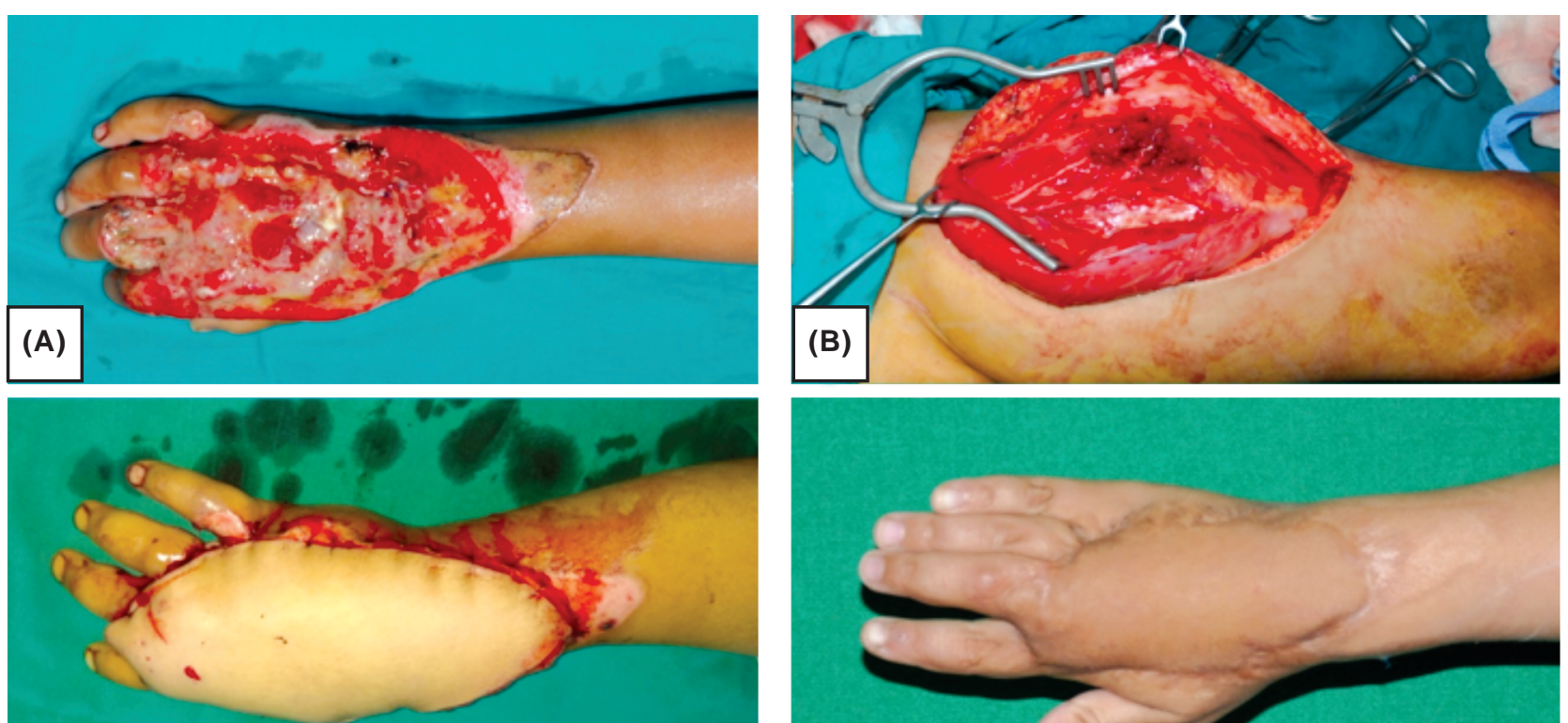

(C)

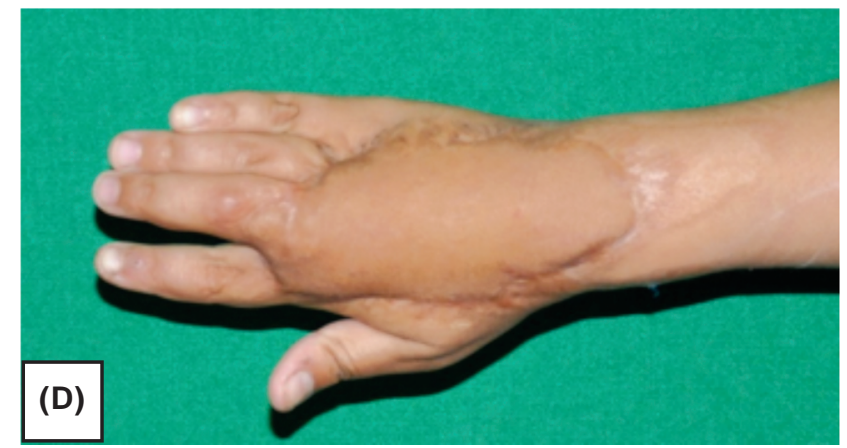

Fig. (2): 5 years old male child with post-traumatic right dorsal hand defect with loss of extensor tendons of ulnar 4 fingers. (A) Pre-operative view. (B) Intraoperative view during dissection of left ALT fasciocutaneous flap based on single musculocutaneous perforator. (C) Immediately after flap transfer. (D) 3 years post-operative after 2 stages of thinning.
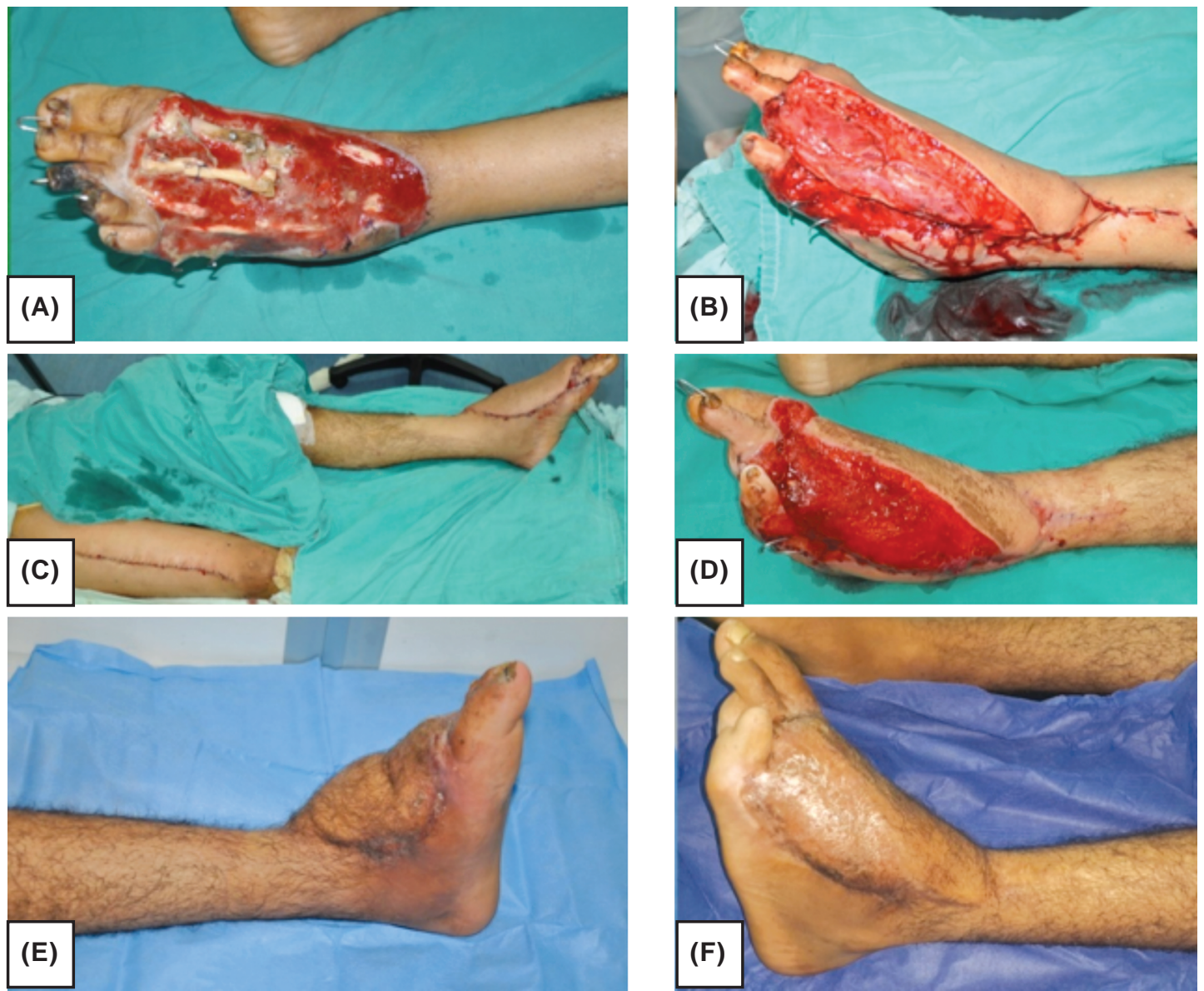

Fig. (3): 21 years old male patient with $11 \times 18 \mathrm{~cm}$ left dorsal foot defect and metatarsal fractures. (A) The defect with exposed metatarsals and devitalized $3^{\text {rd }} \& 4^{\text {th }}$ toes. (B) After coverage with musculocutaneous free ALT flap. The skin paddle and underlying muscle strip were partially moved apart within the safe limits of the 3 musculocutaneous perforators detected. Few quilting sutures are also seen to prevent further shear. (C) Donor site direct closure. (D) 3 weeks post-operative before skin grafting. (E\&F) 1-year post-operative with stable coverage before management of underlying metatarsals osteomyelitis (sequestrectomy and bone grafting) and flap debulking. 

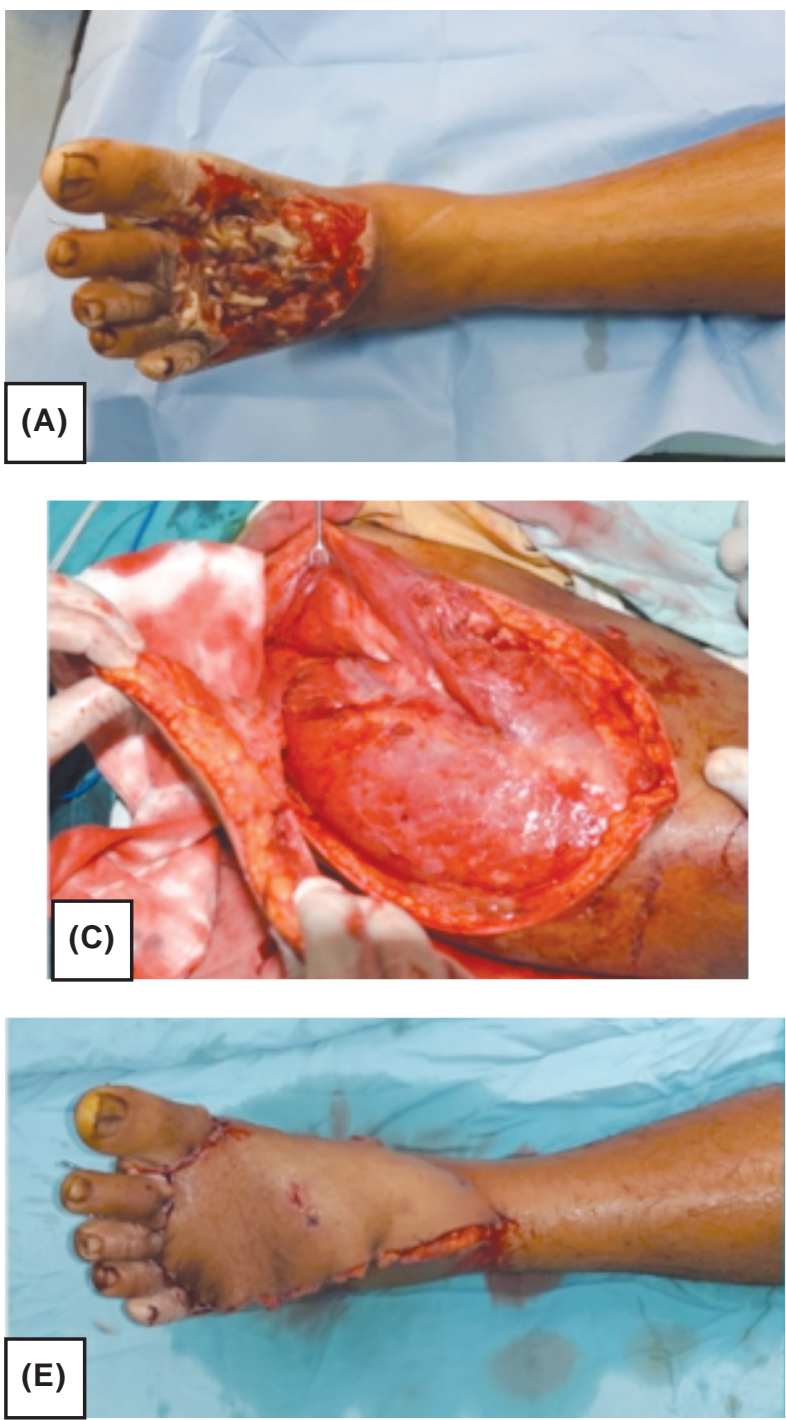
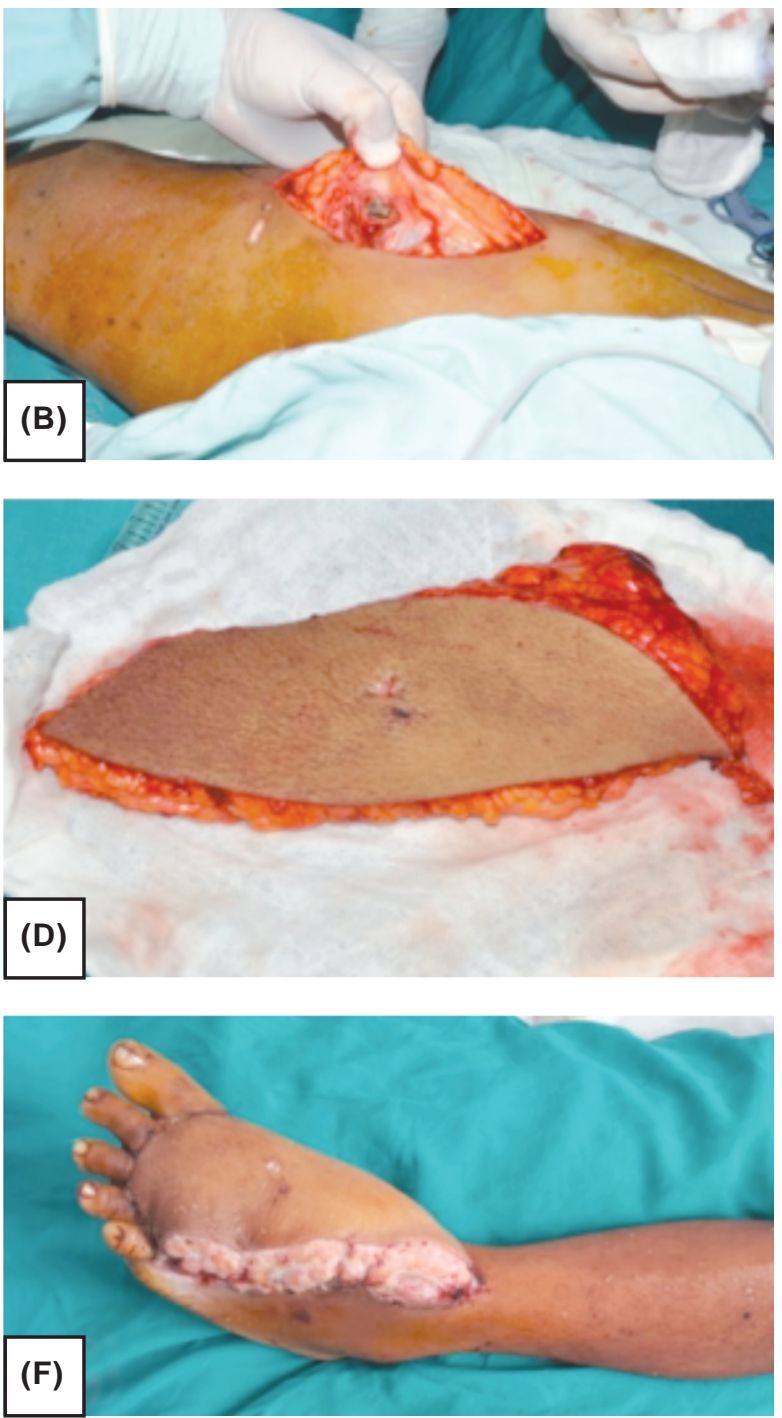

Fig. (4): 23 years male patient with left dorsal foot defect with exposed fractures metatarsals. (A) Pre-operative. (B) During dissection of contralateral ALT flap. Small skin traumatic wound near the center of flap skin paddle discovered to be more significant than thought with associated significant rectus femoris muscle injury and retained FB. The other thigh was having more injury with raw area precluding its use as flap donor (C) Intraoperative view showing a fasciocutaneous ALT flap based on the oblique branch of lateral circumflex femoral vessels terminating as sizable septocutaneous perforator. The descending branch is also seen over the rectus intermedius muscle sending muscular branches to the rectus femoris and vastus lateralis but giving no skin perforators. (D) ALT flap after harvest based on the oblique branch only. (E) After flap inset. (F) 10 days postoperative before discharge with viable flap.

\section{DISCUSSION}

Free tissue transfer underwent substantial improvement over the past three decades, focusing on functional and aesthetic results of reconstruction for both the donor and recipient sites. The free ALT flap is atypical example of this revolution from its early description by Song et al., [1] in 1984 and its later popularization and wide use to reconstruct defects all over the body from the head to toes yielding very good functional and aesthetic results with relatively minimal donor site morbidity making it a workhorse free flap [4,5]. It providesa good size of many tissue types including skin, subcutaneous fat, fascia, muscle, and bone [9-11] with possible sensate flapand flow-through flap for limb revascularization [6]. The flap pedicle is of adequate size and length, 2 team approach is possible in a supine position, and donor site morbidity is minimal especially with direct closure, this is usually possible with flap width up to 8$10 \mathrm{~cm}$.

In the current series, a free ALT flap was used to reconstruct 11 extremity defects (6 UL defects $\& 5$ LL defects). Flaps were harvested based on septocutaneous perforators in 2 out of 11 cases $(18.2 \%)$. The remaining 9 cases $(81.8 \%)$ were 
musculocutaneous perforators. This is comparable to most literature reports $[\mathbf{3 , 8 , 9 , 1 3 - 1 5 ]}$. Septocutaneous perforator pattern offered the well-known easier and less morbid flap dissection reported in the literature. All flaps survived completely except one flap used for the release of post-burn contracted wrist ended with partial flap loss secondary to flap congestion which progressed slowly over few days. Flap venous anastomosis was confirmed patent, and probably inadequate perforator vein was the issue. This was conservatively managed with debridement and later skin graft. Early complicationsalso included minor dehiscence of the donor site in one case that was conservatively managed.

Reconstructed LL defects included 3 dorsal foot defects and 2 lower third leg defects of moderate to moderately large size $(6 \times 10-11 \times 18)$ with exposed bones. Defect location and size precluded any local flap option for coverage. Without thinning, fasciocutaneous flaps thickness was appropriate for the distal third leg defects and moderately bulky for the dorsal foot defects. The single musculocutaneous ALT variant in this series was used to reconstruct alarge $(11 \mathrm{x} 18 \mathrm{~cm})$ dorsal foot defect. This was the bulkiest reconstruction in this series. Conservative flap debulking was done 1 year later during flap partial elevation to managed underlying metatarsal osteomyelitis by sequestrectomy and iliac bone graft after removal of the retained hardware (screws). In comparison, the fasciocutaneous flap variant used to reconstruct the other $4 \mathrm{LL}$ cases wasmore sightly and less bulky. The small number of cases reported in this series would undermine this conclusion, but supporting evidence comes from other literature reports. In larger seriesof 50 pediatric patients with LL defects, Ayad et al., [17] compared traditional free muscles and musculocutaneous flaps to the fasciocutaneous free ALT flaps and reported excellent results with the latter.

Out of the 6 flaps used for UL reconstruction, 3 cases suffered dorsal hand defect with extensor tendon loss, reconstructed by non-thinned (except for flap periphery) fasciocutaneous flap with fascia Lata usedas an intercalary tendon graft. Later flap thinning was done to improve flap shape and hand function. The reconstructed extensor tendons yielded poor to a fair range of motion at MCP joints probably reflecting significant flap bed and joint adhesions augmented by lack of patient compliance with early range of motion exercises, results almost comparable to report by Meky M [13]. Providing both tendon and skin reconstruction in one package represents a clear advantage of free ALT in hand reconstruction. More aggressive post-operative range of motion exercise/physiotherapy asearly as possible after ensuring flap viability/stability (about 2 weeks) would is essential for obtaining acceptable hand function. Patient compliance is crucial.

UL cases included reconstruction of $1^{\text {st }}$ webspace after the release of post-traumatic contracture. Amore aggressive primary flap thinning was employed, after flap harvesting in a subfascial plane, the whole flap deep fat was excised except a periperforator zone of $3 \mathrm{~cm}$ radius. Initially, this was thought ideal with the peri perforator subcutaneous bulk providing both perforator safety and the desired bulk at the center/depth of the released web. Later one stage of minor flap thinning was also performed to improve hand shape and grip function (Fig. 1).

Wong et al., [18] reported an interesting anatomical variation involving the vascular pedicle of the ALT flap in a series of 89 ALT flaps. An oblique pedicle/branch originating mostly from the descending branch of the lateral femoral circumflex artery was present in almost 1/3 of the cases. In $14 \%$ of dissections, it was the source of the main flap perforator. This anatomic variation was encountered in one case (9\%) (Fig. 3D) of the current series. The oblique branch was a sizable direct cutaneous branch given from the very proximal descending branch. It was the sole skin vessel encountered and the flap was solely based on it. It was dissected to its origin from the descending branch where it was divided preserving the descending branch main trunk. The oblique branch was of adequate size for the microvascular anastomosis (about $2 \mathrm{~mm}$ ) to the distal anterior tibial vessel. This was the easiestand least morbid flap dissection in this series.

Subfascial dissection was used in all cases of this series. An easier dissection plane, with easier perforator identification, yielding a thicker flap including the deep fascia. For leg reconstruction usually, this full-thickness flap fits well most reconstructive needs except dorsal foot reconstruction where flaps were moderately bulky. For hand reconstruction, thinner flaps would provide improved contouring and flexibility needed for better hand mobility. In the current series, this was attained or improved with secondary thinning procedures in most flaps used for hand reconstruction. The entire flap thickness incorporating the fascia Lata was needed for tendon reconstruction in 3 cases and debulking was a secondary procedure.

The main disadvantage of subfascial flap dissection is the increased donor site morbidity in terms of higher risk sensory loss of lateral thigh 
and higher possibility of mild/transient weakness from muscle dissection. The latter is more common with significant intramuscular perforator dissection and of course main motor nerve injury and musculocutaneous flap variant [3]. In the current series, a musculocutaneous flap was harvested only in one case with a relatively large $(11 \times 18 \mathrm{~cm})$ foot defect. In this case, 3 small musculocutaneous perforators with long intramuscular course promoted conversion to musculocutaneous flap variant with reduction of skin paddle to $8 \mathrm{~cm}$ only to permit donor site direct closure avoiding the added morbidity of skin grafting after muscle harvest. The already eccentric skin paddle location in relation to the harvested muscle strip was accentuated by a more lateral slide of the skin paddle within the safe limit of visualized connecting perforator to gain more flap width.

\section{Conclusion:}

Free ALT flap is a reliable, versatile reconstructive option for small to moderately large limb defects. Donor site morbidity is minimal with direct closure.

\section{REFERENCES}

1- Song Y.G., Chen G.Z. and Song Y.L.: The free thigh flap: A new free flap concept based on the septocutaneous artery. Br. J. Plast. Surg., 37: 149-159, 1984.

2- Xu D.C., Zhong S.Z., Kong J.M., et al.: Applied anatomy of the anterolateral femoral flap. Plast. Reconstr. Surg., 82: 305-310, 1988.

3- Koshima I., Fikuda H., Utumomiya R., et al.: The anterolateral thigh flap: Variations in its vascular pedicle. Br. J. Plast. Surg., 42: 260-262, 1989.

4- Wei F.C., Jain V., Celik N., et al.: Have we found an ideal soft-tissue flap? An experience with 672 anterolateral thigh flaps. Plast. Reconstr. Surg., 109: 2219-2226, 2002.

5- Chen H.C. and Tang Y.B.: Anterolateral thigh flap: An ideal soft tissue flap. Clin. Plast. Surg., 30: 383-401, 2003.

6- Koshima I., Kawada S., Etoh H., et al.: Flow-through anterior thigh flaps for one-stage reconstruction of softtissue defects and revascularization of ischemic extremities. Plast. Reconstr. Surg., 95: 252-260, 1995.
7- Zhang Q., Qiao Q., Yang X., et al.: Clinical application of the anterolateral thigh flap for soft tissue reconstruction. J. Reconstr. Microsurg., 26: 87-94, 2010.

8- Koshima I., Yamamoto H., Hosoda M., et al.: Free combined composite flaps using the lateral circumflex femoral system for repair of massive defects of the head and neck regions: An introduction to the chimeric flap principle. Plast. Reconstr. Surg., 92: 411-427, 1993.

9- Lin C.H., Wei F.C., Lin Y.T., et al.: Lateral circumflex femoral artery system: Warehouse for functional composite free-tissue reconstruction of the lower leg. J. Trauma, 60: 1032-1036, 2006.

10- Brody R.M., Pandey N.C., Bur A.M., et al.: Anterior lateral thigh osteomyocutaneous free flap reconstruction in the head and neck: the anterolateral thigh osteomyocutaneous femur bone flap. Head Neck, 38 (12): 1788-93, 2016.

11- Worley M.L., Patterson T.M., Graboyes E.M., et al.: Association of the anterolateral thigh osteomyocutaneous flap with femur structural integrity and assessment of prophylactic fixation. JAMA Otolaryngol. Head Neck Surg., 144 (9), 2018.

12- Seth A.K. and Iorio M.L.: Super-Thin and suprafascial anterolateral thigh perforator flaps for extremity reconstruction. J. Reconstr. Microsurg., 33 (7): 466-73, 2017.

13- Meky M.: Versatility of Anterolateral Thigh Flap in Dorsal Hand Reconstruction. Egypt. J. Plast. Reconstr. Surg., 42 (2): 311-315, 2018.

14- Kholousy H.M., Elkafrawi H. and Farouk A.: The Versatility of the Free Anterolateral Thigh Flap in Reconstruction of Soft Tissue Defects in the Extremities. Egypt. J. Plast. Reconstr. Surg., 43, (1): 25-29, 2019.

15- Abdel-Khalek A., Allam A., Hendy A., et al.: Clinical Evaluation of Free Anterolateral Thigh Flap in the Reconstruction of Major Soft Tissue Defects in the Leg and Foot. Egypt. J. Plast. Reconstr. Surg., 27 (2): 173-180, 2003.

16- Zakaria Y.: Anterolateral Thigh Perforator Flap for Reconstruction of Lower Extremity Soft Tissue Defects. Egypt. J. Plast. Reconstr. Surg., 39 (1): 73-78, 2015.

17- Ayad W., ElGamal M., Farahat A. and El Batawy A.: Microsurgical Reconstruction of Traumatic Lower Extremity Defects in Pediatric Patients: Is Fasciocutanous Flap A Versatile Tool to Replace Musculocutaneous Flap? Egypt. J. Plast. Reconstr. Surg., 43 (1): 129-132, 2019.

18- Wong C.H., Wei F.C., Fu B., et al.: Alternative vascular pedicle of the anterolateral thigh flap: The oblique branch of the lateral circumflex femoral artery. Plast. Reconstr. Surg., 123: 571-577, 2009. 